\title{
ANNOTATION
}

\section{Education of Children with Defective Sight}

The paper by Professor Kaz which we publish in this number is one more piece of evidence of the interest being taken at the present time in a matter of great importance. He asks some pertinent questions and we gather that in the U.S.S.R. various methods of dealing with partially sighted children have been tried. He appears to lay great emphasis on the need for adequate supervision of the child's general health, if we understand his allusions to physiotherapy aright. And of course the importance of this is paramount. It is obvious that children who are for practical purposes totally blind are only suitable for education in schools for the blind. He makes no direct mention of the myope classes which have been so successful in this country and elsewhere, it may be that these are included in the sight-saving classes of which he speaks. We do not know if the incidence of myopia in the U.S.S.R. is heavy or not; but if it be, we think that the U.S.S.R. would be well advised to institute such schools in the great centres. The problem of the education of the child with markedly defective sight is a difficult one. In our view much depends on the age of the child at the time that the condition causing the defect arose. If a child's defect be congenital or arises very early in life it has probably forgotten what good sight was like when the time for school coines. Then again the definition of blindness is difficult. All must have met in practice many people with very defective vision as measured in terms of Snellen's test types, who have not only not complained of their defect, but have managed to lead active, useful lives. It may be argued that such patients acquired their defective sight in most cases after the school period ended, and so should not be included in an annotation on the education of children with defective sight. Such remarks, of course, apply more to those of literary tendencies than to those engaged in such work as cabinet-making. We know of a patient who can still read quite well with his glasses, if he holds the book close; but no combination of lenses will give him $6 / 60$.

The definition in force in this country "so blind as not having sufficient sight to be able to see work for which sight is essential " is purposely vague, and it is doubtful if a more satisfactory definition can be arrived at. But if we are to define blindness in terms of visual acuity there would seem to be much in favour of the definition given by Miss C. Edith Kerby and alluded to in an annotation on page 99 . Our readers may remember that she postulated five groups, the best sighted of which were the border-line cases with vision of about $6 / 60$; the other groups included such classes as perception of motion, travelling sight, ability to read large head lines. The border-line group contains cases where there are field defects which may counterbalance a better acuity than $6 / 60$. 